\title{
Queer Incrementalism and the Emancipatory Rhetoric of Redemption on FX's "It's Always Sunny in Philadelphia"
}

\author{
Michael Johnson Jr., Ph.D. \\ California State University - Northridge
}

\begin{abstract}
This research critically examines the life of Mac Reynolds on the popular cult comedy It's Always Sunny in Philadelphia. Here I argue that Mac's character represents a careful strategy of "queer incrementalism" in which ostensibly gay characters are introduced following a predictable path of marginality, whereby their sexual identities are slowly uncovered over the course of time in keeping with the prevailing social discourses of palatability. Simultaneously, Sunny uses satire because of its heavy reliance on the ability of sketch comedies like it to, 'avoid the unpleasant effects of its own situations"” (Mellencamp 1997), thereby rendering its messages communicatively nonthreatening and ensuring the series economic profitability. Finally, I critique the use of redemptive rhetoric that perpetuates the utility of emergence narratives from the closet as a means of self-congratulatory praise that undermines critical analyses of queer characters in the media, and on television in particular.
\end{abstract}


It's Always Sunny in Philadelphia (herein referred to as Sunny) is a popular sketch comedy, originally appearing on the FX network, currently airing its $13^{\text {th }}$ Season on FXX. Created by Rob McElhenney (who also plays Ronald "Mac" McDonald) and Glenn Howerton (who also plays Dennis Reynolds), the series follows the exploits of "the Gang" who include Mac and Dennis, as well as Charlie Day (Charlie Kelly), Kaitlin Olson (Deandra "Sweet Dee" Reynolds), and Danny DeVito (Frank Reynolds). The series has accumulated 144 episodes over its $13^{\text {th }}$ seasons, typically running 25 minutes each. The setting of the series is usually "Patty's Pub" located in a warehouse district in South Philadelphia, where the gang's various exploits typically originate. Mac is coowner of the bar and is Charlie's childhood friend, and Dennis's high school friend (and later roommate). Kelley West cogently describes the series as follows:

These guys lie, cheat, steal and are willing to step over each other to get whatever it is that they want at the time. At the end of the day though, they're like a family a really dysfunctional family... It seems that, like South Park, each episode of Its Always Sunny centers on some kind of serious issue or topic, be it political, religious or social...I think what makes this work is that the characters are such messes that you can actually laugh at them and at the same time, find yourself rooting them on occasion, even if what they're doing is morally abysmal. (2007)

Over the course of the series, its gained significant acclaim. Emily Nussbaum of The New Yorker praised the show, calling it "not merely the best sitcom on television but one of the most arresting and ambitious current TV series, period" (2013). Sunny has consistently received high ratings on review aggregator Metacritic, receiving 70/100,78/100 and 85/100 for Seasons 4, 5 and 6 respectively, and receiving an 86/100 for Season 9 (Metacritic 2013). It's popularity as a cult hit was first observed with reviews from the very beginning in which critics described the series ".... like Seinfeld on crack," a quote that became widely used to describe the series by others (Mellor 2012, Storm 2008). By 2014 the series was listed as \#7 in the "26 Best Cult TV Shows Ever" by Entertainment Weekly. And in 2015 the series popularity was sedimented with a review by Rolling Stone writer Noel Murray who observed that "for 10 seasons, the series had mined comic gold from the execrable behavior of the owners of Paddy's Pub" (2015). FX has capitalized on the series' cult following by carefully creating narratives that appeal to the series target audience which are comprised of viewers who are "hip, sophisticated, [and] urban-minded... with a distinctly edgy and ironic sensibility" (Becker 2004), and who are at least marginally knowledgeable about LGBTQ issues by virtue of their educational attainment, socioeconomic status and cosmopolitan sensibilities. And the incrementalism demonstrated by the series is part of a larger economic practice in contemporary television today which Griffin made abundantly clear a decade ago when he noted that "The television industry is increasingly using gay-themed content to narrow cast to a distinct audience segment that often includes but is not limited to gay male viewers - a demographic that has become known as the 'quality audience' in media parlance" $(2008,356)$.

Although the series is a sketch comedy whose character's absurdity has earned great acclaim, the value of this series for our purpose lies in its ability to satirically interrogate depictions of gay male sexuality through Rob McElhenney's character "Ronald 'Mac' McDonald". Pop 
culture exemplars like It's Always Sunny can (and often do) play an important role in visibly challenging these social distinctions of human sexuality by illuminating their constructedness, while potentially undermining the power structures upon which those constructs are erected and maintained. I contend that It's Always Sunny offers up a safe, unthreatening interpretation of what queer masculinity and same sex desire should look like, sound like and be defined as within American television. Mac's character represents the difficulties associated with depicting gay male sexuality on contemporary cable television, especially in terms of how his character approaches coming to terms with his sexuality and its public meaning within the strict business model of televisual profitability.

Using textual and discursive analyses, this research argues that It's Always Sunny dramatizes the dysfunctional quality of Mac's character, his relationships, and the status of same sex desire on the series whereby Mac's sexual identity is incrementally revealed over the course of 13 seasons. This process of incrementalism is important for the purposes of our analysis, as it exemplifies how Fox (the parent network of FXX) strategically addresses alternative sexualities on US cable television - a market perpetually dependent upon viewer ratings much more than premium networks like HBO or Showtime whose revenue originates from subscription fees. I further argue that this incrementalism reflects the network's decision to permit the series to satirically address the enfranchisement of sexual minorities through its comedic tradition without jeopardizing its highly profitable cult following. Ron Becker contends that gay male representation is directly affected by the industry's quest for revenue:

[television] executives have incorporated gay and lesbian material in their...line ups in order to attract an audience of 'sophisticated', upscale, college-education and liberally minded adults...This programming strategy also has the advantage of targeting a distinct segment of that demographic group, namely, middle-and upperclass gays $(2004,389-390)$.

Incrementally including gay subjects, themes and characters has proven to be a valuable strategy for Fox, but it also has the unfortunate consequence of also "creating a dispersal of often superficial knowledge about gay men and gay culture into the living rooms" (Becker 2004) of American audiences. And while all the main characters are disturbingly flawed, including Mac, they all are completely blind to how their behavior might affect the people around them. Mac remains the object of many jokes regarding his sexuality even as he struggles with his sexual identity amidst repeated attempts to remain firmly in the closet and publicly heterosexual. The series is filled with intertextual references to homosexuality, gay identity, and queer masculinity. This intertextuality is in keeping with the aesthetic and genre conventions of a satirical comedy which are frequently employed in similar series like Reno 911! (Griffin 2008), South Park (Gournelos 2009), and Parks $\&$ Recreations. Viewers of the series do not have to be gay to recognize some of the stereotypical characteristics associated with Mac's gayness, but they do have to be somewhat familiar with gay culture to recognize how the closet works within the setting of the series. By being "in" on the intertextual references offered by the series, one can decipher how these codes refer to gay 
sexuality and thus, Mac's closeted-ness. It's Always Sunny utilizes these intertextual conventions in tandem with its cult audience which is comprised of "knowing viewers" who possess the cultural knowledge and insight to decode and decipher its subtextual messages about gay masculinity and same sex desire. What is especially ripe for analysis, however, is how this process of "queer incrementalism" has generated a wealth of sycophantic acclaim that traffics in the worst kinds of self-congratulatory praise. And that praise invariably fails to critique the fact that visibility often takes a decade or more (in the case of Mac's character) to achieve. Moreover, the path to that enfranchisement often takes a reluctant and halting emergence and conditional acceptance. Thus, I hope to demonstrate in the following pages (1) how the series viewers are enlisted in this process, (2) how same sex desire and sexuality function within the genre of satire, and (3) chronologically assess and evaluate Mac's character development.

\section{Cult Television \& Its Viewers}

The attraction to a series like It's Always Sunny reflects a type of desire in the form of 'epistemophilia', or the desire to know. Indeed, many viewers manifest this epistemophilia through an attraction to "their" characters. Committed viewers ${ }^{1}$ are interested in what happens to the characters-how they develop relationships, how they cope with various obstacles week after week, and season after season. I argue that the same mechanism is true for It's Always Sunny viewers. Not only did FXX announce that it had picked up the show for an additional two seasons (13 ${ }^{\text {th }}$ and $14^{\text {th }}$ ) running through 2019, but that decision also made It's Always Sunny the longest running liveaction comedy in cable history. The series cult following is best illustrated by fans reaction to the series removal from Hulu. Chris Albrecht noted that when Hulu dared to remove the series in January 2009, "Fans got extremely upset and started flaming the Hulu message boards and flooding Twitter with negative comments about Hulu" (2009). According to Sheila Seles, Hulu took note and Hulu CEO Jason Kilar posted an apology to the Hulu Blog...resulting in It's Always Sunny return to Hulu $(2009,26)$. Cultu viewers who regularly watch the series self-identify as "cult" viewers as they "watch TV in order to participate in niche communities both online and offline...viewers participate in subcultural communities because of an affinity for particular content" (Seles 2009, 19). Moreover, audiences can find themselves identifying with the characters ability to circumvent, or in some cases directly reject, the common social conventions associated with life in a civil society. One need only watch a single episode to see how these characters pursue their various schemes, and yet despite their antics, frequently escape punishment by social authorities.

Mac's character is important to the series and our analysis by virtue of his centrality to the Gang's exploits, especially in terms of how his cisgendered gay masculinity functions within the metanarrative as a foil to the Gang's uniform heterosexuality. And by examining Mac, we can thus infer meaning derived through his dialogue, actions and behaviors which has enormous potential to affect the attitudes and values of the series cult audience (Papa 2000) towards gay men and same sex desire in particular. Marie Gillespie notes 'knowing what and whose stories get told or remain untold is crucial to understanding the exercise of power in society. Stories about events 
and characters, real or fictional, may be shaped in ways that serve the interests of powerful institutions such as governments or business"' (2006, 83). And given FXX and Fox's financial interests in the series profitability, issues of any character's sexuality continue to be relevant (Himberg 2018). As Julia Himberg makes abundantly clear, in today's televisual landscape "television marketers try to build niche outlets dedicated to underrepresented minorities... [that create] inclusion for sexual minorities and also turn sexuality into an effective marketing tool to draw high-quality audiences" $(2018,132)$.

It's Always Sunny fandom reveals much about the expectations that these cult audiences have for the show's characters as much as it might for other formal elements like plot, format, duration, etc. Cult viewers do not derive meaning within a vacuum but from the same societal ideologies that proliferate through contemporary society. John Fiske makes clear that characters are not simply reflective, non-productive facsimiles, but rather operate as 'metonymic representations of social positions and the values embedded in them' $(1988,158)$. It's Always Sunny producers (who are also its actors) create the scenes, characters and plots found in the series to which cult viewers become acclimatized to seeing. Television series that do not garner viewer loyalty die quick deaths and central to that loyalty is popularity gained through a careful navigation of personal values and morals which can be challenged in the sketch comedy genre. Within this genre, Sunny can appear to undermine prevailing consensus on controversial issues without alienating viewers enough to quit watching the series, or actually undermining the status quo, thus safely securing its profitability. My own analysis of culturally valued "popular series" reveals the importance associated with the communicative power television possesses in conveying discrete messages about same sex desire, and gay male identity that does not exists with "less popular" television series $(2016,2010)$. Maxwell McComb once famously observed that although the media "may not be successful much of the time in telling people what to think, it is stunningly successful in telling its readers what to think about" (2004) [emphasis added]. It's Always Sunny, and in turn FX, have reaped substantial financial and social rewards from the careful negotiation of the series treatment of homosexuality and same sex desire, but it has done so by pursuing a strategy of safety that sometimes re-inscribes some of the same damaging tropes it seeks to critique.

\section{Satire and Sexuality}

It's Always Sunny is at its heart a comedy that uses satire and parody to illustrate a wide variety of absurd perspectives about a number of contemporary issues. Similar in some respects to other shows like Seinfeld, It's Always Sunny uses comedy to entertain, but comedic entertainment has both "boundaries and constraints" and those boundaries are lightly policed while the constraints are minimal, even when "self-imposed by individual networks or policed by the FCC... and there are informal, unspoken rules that society seems to expect its comedy to heed" (Peifer 2012, 263264). It's Always Sunny makes a habit of instigating viewer discomfort by virtue of its comedic parody of socially taboo issues. Over the course of the 13 seasons the cast have talked about such things as: orgies, glory holes, drug addiction, pedophilia, and selling babies....to name a few. And as Jason Peifer makes clear, "Humor thrives on being irreverent, outrageous, surprising and even 
licentious. As comedy frequently involves "pushing the envelope" $(2012,264)$. One might conclude that the way in which It's Always Sunny tackles the taboo subjects it critiques, resonates strongly with its target audience, especially given its longevity. If this is true, then the series "has addressed topics most shows are incapable of covering or unwilling to cover" (Schepler 2014) thus offering its viewers an interesting, guilt-free vehicle by which to speak about subjects and issues precious few others dare to discuss. That alone makes It's Always Sunny a valuable cultural commodity.

According to Diana Schepler, McElhenney said that the five main "characters are just a cross section of the American public...ultimately we're just taking a look at American culture" $(2014,2)$ and its character's depravity and deplorable nature work as a satirical way of effecting that examination. While Tim Goodman points out that "Sunny has matured into a subversive, ridiculously over-the-top show that manages to keep its brain active while tweaking social and political correctness" (2010) it doesn't actually subvert existing structures in any substantive way beyond achieving laughs. Marianne Eloise brilliantly notes that the genius of the series is its ability to make light of serious issues... "When watching a group of deplorable people make contemptible decisions, we aren't likely to identify with any of them" but it can "make us consider or own prejudices and mistakes, no matter how comparatively small" and their "jokes...express an unusual amount of intelligence and empathy when dealing with sensitive subjects" (2016). As a type of satire, the series offers several important critiques which appear to challenge the centrality of the repronormative, hegemonic heterosexuality commonly associated in the popular consciousness as the default of American culture. Proceeding chronologically through the series, one finds several examples where these concepts appear, and our focus will be how they're addressed through Mac McDonald. McElhenney (who plays Mac) explains that the series "has always been about deconstructing the sitcom...the traditional sitcom is always about making the characters more likeable, making them more nice...we...thought, 'Well let's just do the opposite of that. Let's try to make them as deplorable as possible"” (Keller 2011).

\section{Mac McDonald}

Mac's character engages in a carnivalesque insanity much like the rest of the Sunny protagonists do, but Mac's relationship to events in the series are drawn from contemporary events related to his thinly disguised queer sexual identity. Mac's character is generally characterized by a type of hypermasculinity that stems from deep seated insecurities over his sexual identity. Thus, his comments and actions are very often hyperbolic, are usually met with amazement and embarrassment by the gang whose collective incredulity reflect their suspicions over Mac's latent homosexuality. Much like South Park's Mr. Garrison, hints about Mac's homosexuality “continue but are never quite unequivocal. In fact, his sexuality remains in flux through the series" (2009, 273-274) at least until the end of Season 13 which just began airing in January 2018. Ted Gournelos describes such hyperbolic homosexuality as "an acceleration of existing rhetorical norms, through which stereotypes and identity categories are exaggerated to highlight logical fallacies in their construction" and viewers see repeated examples of these exaggerations in 
innumerable episodes of the series. Moreover, Griffin argues that "Representations of gay men are increasingly visible on both television and in American popular culture in general. The popularity of televisions programs featuring gay male protagonists...has widely dispersed knowledge about camp and queer masculinities in a way that makes familiarity with a character..." $(2008,368)$ like Mac both plausible and inevitable.

\begin{tabular}{|c|l|l|c|}
\hline Season & Episode & \multicolumn{1}{c|}{ Title } & Date \\
\hline 1 & 1 & The Gang Gets Racist & $8-4-2005$ \\
\hline 1 & 4 & Charlie Has Cancer & \\
\hline 3 & 7 & The Gang Sells Out & \\
\hline 3 & 10 & Mac Is a Serial Killer & \\
\hline 5 & 9 & Mac and Dennis Break Up & $11-12-2009$ \\
\hline 6 & 1 & Mac Fights Gay Marriage & $11-16-2010$ \\
\hline 8 & 5 & The Gang Gets Analyzed & \\
\hline 9 & 5 & Mac Day & $10-2-2013$ \\
\hline 13 & 10 & Mac Finds His Pride & $11-7-2018$ \\
\hline
\end{tabular}

From the beginning, in Season 1, Episode 1, "The Gang Gets Racist" we see Mac being enlisted to manipulate his straight friend Dennis “...into getting 'black out' drink while Dee asks a favor from one of her acting friends. Dennis awakes to find what he thinks is a long-haired blonde woman in his bed only to find out that he has had sex with not one, but two men, while intoxicated" (Ladenburg 2015, 873). This solidifies Mac's utilitarian value to the group but also communicates to the audience Mac's utility as a sexual manipulator but also where his character lies within the cisgendered heteronormative hierarchy of the Gang. By episode 4 of the same season, "Charlie Has Cancer" we find that Mac attracted to a FTM transsexual named Carmen who "... is so attractive, Mac did not even notice, as Dennis points out the 'unmistakable bulge of a large penis' in Carmen's Jeans. At 6:00 Mac goes to Carmen to confront her for lying to him about her gender" (Schepler 2014, 4) whereupon Mac is disarmed through her compliments about his body, ultimately relaxing and becoming unbothered by her male genitalia. The next time we see Carmen is at 15:17 where Mac uses a friend's cancer diagnosis to seduce Carmen. However, by Season 3, Episode 7 "The Gang Sells Out" we find Mac discussing the infinite details about the difference between a regular bottom and a power bottom during sex, thereby demonstrating his "insider knowledge" (Taylor 2011) of the sexual dynamics of gay sexual positions and their power relationships - subjects that few exclusively heterosexual men would know. This further solidifies Mac's identity as a closeted gay man in the series narrative.

By Season 3, Episode 10 "Mac Is a Serial Killer" we find Mac still dating Carmen and from 16:12 - 16:47 Mac ends his relationship with Carmen telling her "he had fun" but that "I don't care if people see us together. I just don't want them to think we're dating" adding when Carmen grows more agitated "I'm not ashamed of you. I'm ashamed of myself". Here Mac's admission replicates the "tortured gay" or "Gayngst" stereotype which says that closeted gay characters "tend to be miserable a lot, and not by simple coincidence - their misery can be attributed largely to their sexuality, or more accurately, other people's attitudes towards it. In short, 
they don't have angst, they have gayngst" (TV Tropes 2010). This stereotype perpetuates the belief that character's self-loathing, or rampant homophobia towards themselves and others is commonplace, and therefore normal. The replication of this kind of stereotyping through Mac's character is damaging because it "usually portrays gay people sympathetically and addresses an issue many gay people in real life go through, it can be interpreted as saying that it's impossible to be gay without being miserable, or that gay people don't deserve [happiness], or...that gay relationships are innately disastrous" (TV Tropes 2010). Moreover, the use of the "gayngst" trope follows a predictable, formulaic narrative path in which "the character will eventually come to terms with their sexuality, have the obligatory Coming-Out Story, and either live happily ever after with their love interest, or morph into some other gay archetype". And as we will see Mac's development as a character mostly follows this chronology (albeit in a very exaggeratedly slow fashion). Mac's gaynst continues into Season 5, Episode 9 "Mac and Dennis Break Up" where he and Dennis decide to attempt living apart after a visit by Dee results in an accusation that their relationship resembles that of an old couple. The results end in failure and with Mac and Dennis reuniting due to their complete inability to live alone. But their failure is hallmarked by expressions of deep emotional attachment, and a longing for physical intimacy and companionship from Mac which drives him back Dennis's embrace. The message clearly stating that Mac's happiness is predicated on the love from a straight man and that he will be perpetually unhappy and unfulfilled absent that affection.

Indeed, by Season Six, Episode One "Mac Fights Gay Marriage" Mac's susceptibility to criticisms about his sexual fluidity result in a case of conflicted emotions when he learns that Carmen (from pervious episodes) has finished her sexual reassignment surgery. This results in Mac protesting against gay marriage in retaliation for Carmen's rejection but it also reveals Mac's stereotypical self-loathing, internalized homophobia and insecurity about his own sexuality having had sex with Carmen in her pre-surgical state. Indeed, Mac's inner turmoil is only enforced when in Season 8, Episode 5 "The Gang Gets Analyzed" Mac accuses his psychiatrist of "leaving a pen in front of him because it looked like a penis. This, Mac believed, was the shrink's way of telling him that he was gay. Mac flatly denied this, but undercut his case by unconsciously popping the pen into his mouth later" (Hanson 2010). Unsurprisingly then by Season 9, Episode 5 "Mac Day" Mac proceeds to ask the Gang to grease anonymous bodybuilders in keeping with the description of the $6^{\text {th }}$ day of creation in which Man was made. But by this point, the Gang has come to realize that Mac isn't a straight man interested in ostensibly non-homosexual sex with men, but rather a gay man desperately trying to maintain his straight identity from within the closet of his own making. Which leads us finally to Season 13, Episode 10's penultimate coming out scene in "Mac Finds His Pride". In this scene Mac has come to terms with being out publicly but "doesn't know where I fit in as a gay man" (0:55). The episode revolves around Frank enlisting Mac to perform as their token gay on a pride parade (by which he and the others will earn money) but to accomplish this, Frank assumes the job of "finding" Mac's gay "pride". That Mac acquiesces to this further demonstrates his subservient position within the heteronormative hierarchy of the gang, and also communicates the stereotype that gay men are perpetually inferior to heterosexual society and their 
instrumentality is only defined by the needs of heterosexuals like Frank, Charlie and Deandra who need his help to make money by dancing on their float (which hopes to increase the Bar's visibility and profitability to the gay consumers of the parade). By the end of the episode, Mac has come out to his father through an interpretive dance that follows his public declaration of "Dad, I'm gay" (15:17). The critical acclaim of this moment in the otherwise unremarkable narrative of the episode, has been overwhelmingly positive. Some examples of this praise are instructive:

What happened at the end of season 13 may change its course and tone forever. 'I do not know if 'It's Always Sunny In Philadelphia' is the same show after this," wrote The A.V. Club's Dennis Perkins. For McElhenney and Day to conclude their creation's 13th season with such a devastatingly, unprecedentedly heartfelt and redemptive arc for one (and maybe two) of 'the worst people in the world' suggests that they have plans to take their show into another direction entirely" (Tanenbaum 2018) [emphasis added].

Such effusive praise fails to account for the time within which Mac's closeted sexuality remained the point of many jokes and, thereby became the source of the series cast and creator's paternalistic redemption.

But no, it [Mac's dance scene] sounds like it was meant to be a sincere moment of emotional validation for a character who has always struggled with their identity.... Everything about the scene was created by going through the path of most resistance. And it works. Beautifully...Mac's father may have missed much of the performance, but sharing ourselves with others this way is only partially about the reactions of the audience. Mac found himself this season, and then presented that struggle in the most...shocking direction it could have this season: earned, emotional, honesty" (Kuchera 2018).

Fascinatingly Kuchera waxes effusively about the beauty of Mac's performance. And it was beautiful, but its necessity to the story is all but avoided. The sharing that Kuchera invokes replicates the necessity of the closet and emergence narratives from the closet by gay men whose secrecy is born from homonormativity and social discrimination which put them there in the first place. Mac's "finding himself" was only necessary because heternomorative society has made the discovery of one's (only recently) deviant sexuality a despicably unavaoidable rite of passage for gay men. Liz Baeseller describes this episode's dance as

Gorgeous, heartbreaking, life-affirming, and not in the slightest bit funny, the last five minutes of "Mac Finds His Pride" are a departure from almost every convention Always Sunny has ever set up. And at thirteen years, those conventions were firmly set indeed. The show has always had a good heart, but it's never shown it in earnest...Undertaking such a drastic departure is immensely brave, and executing it flawlessly (the only way the risk could truly pay off) is worthy of 
endless praise. I'm honored to get to write about it, and I look forward to adding it to every list I can in the coming weeks" (Baeseller 2018).

Incomprehensively Baeseller waxes emotional about this episode by arguing that Mac's performance is "life affirming" but if that is true, and I'm not certain it is, the only reason it's an accurate depiction is because some (gay) lives are under attack and are being devalued. Moreover, she notes that Mac's emergence in the form of choreography has taken 13 years but incongruously and inexplicably then congratulates the same series for "always" possessing a "good heart" and that the series bravery merits "endless praise". Yet Baeseller was also the same person who only months earlier criticized the series "creeping progressivism" (2018). Indeed, her criticism that "by 2010 transphobia and homophobia are no longer funny, even coming from people as horrible as the gang...Instead, all of their negative attitudes are funneled into Mac, who himself becomes more and more overtly gay" remains an accurate assessment of the series but is irreconcilable with her more recent uncritical praise after Season 13's final episode. The overwhelming press and critical reception to Mac's choreographic dance and public announcement to his father has been egregiously positive to the point that one must question what is actually being celebrated. I argue that the profundity of this praise isn't simply the joy of another "successful" coming out story on television. Instead, the breadth and unanimity of this praise seems to embrace a kind of redemptive rhetoric that embraces these emergence narratives with a zealousness that proves their superficiality. This rhetoric of redemption functions through congratulatory praise without having to acknowledge the financial stratagems of profitability that demand "creeping progressivism" and queer incrementalism in the media; indeed even queer media has replicated this rhetorical strategy in its praise for the series (albeit far less evocative and more sobering in its analysis). And my criticism of this rhetorical praise has not even broached the issue that Mac's (gay) character is played on screen by a heterosexual man, which some have argued is equally as problematic given the availability of equally qualified gay men in the industry (Martin Jr. 2018).

\section{Conclusion}

In much the same way, as South Park has proven to be both a "lucrative and oppositional form of popular media" $(2009,271)$ It's Always Sunny has followed a similar trajectory of both economic and cultural profitability generating dependable revenue year after year and maintaining its social value primarily through its appeal to a primed cult audience receptive to its irreverent cultural criticisms. Although Ted Gournelos convincingly argues that It's Always Sunny "aggressively exaggerates and shocks" as much as it "can be seen as both reactionary and progressive...by castigating a culture that reifies its [heterosexual] identity" (2009, 282-283) every debate raised in each episode are "always red herrings in the end, and any social satire" defused those issues by their conclusion (Perkins 2015). While the Sunny formula requires the gang to "never be entirely beyond the reach of the viewer's understanding" their "individual failings and pain are identifiably human enough that it draws us, at least, within compassion's range" (Perkins 2015). Unfortunately, the series also capitalizes on safe depictions of gay stereotypes by taking 13 years to finally arrive at a point where Mac's character emerges from his (very profitable) closet. Moreover, it reifies 
some of the most damaging stereotypes about gay identity and queer sexuality in keeping with prevailing discourses of palatability that's managed through the strategic use of satire to immunize itself from criticism that it otherwise might generate were the series in another genre of television. What's equally discouraging in terms of queer liberation is the self-congratulatory, emancipatory rhetoric of redemption that has followed Mac's emergence from the closet, and the acclaim that the series network has accrued despite the incrementalistic chronology employed by its cisgendered, heterosexual creators responsible for Mac's every word, decision and action. So where does the series go from here? Considering news from Rob McElhenney who recently observed that "I think finally we're going to have to have Mac have a love interest," at the Season 13 premiere (Venable 2018), critics will wonder if the renewal of a $14^{\text {th }}$ Season and the emergence of a boyfriend will signal a change in the messages about gay men and same sex desire? Will Mac have a sex life or become one of the innumerable caricatures of gay men on television whose visibility is always accompanied by sexual abstinence? I don't know what's next for Mac, but I certainly hope that it doesn't take another 13 years for Sunny to move into the $21^{\text {st }}$ century. 


\section{Bibliography}

Albrecht, Chris. 2009. Hulu Yanks Sunny, Viewers Don't Find it Funny. January 13. Accessed June 26, 2012. http://newteevee.com/2009/01/13/hulu-yanks-sunny-viewers-dont-find-itfunny/.

Baeseller, Liz. 2018. "How 'It's Always Sunny in Philadelphia' Delivered The Best Scene of 2018." FilmSchoolRejects.com. November 8. Accessed March 22, 2019. https://filmschoolrejects.com/best-scene-2018-always-sunny/.

Baessler, Liz. 2018. "The Creeping Progressiveness of 'It's Always Sunny in Philadelphia'." Film School Rejects. July 11. Accessed February 17, 2019. https://filmschoolrejects.com/progressiveness-its-always-sunny-in-philadelphia/.

Becker, Ron. 2004. "Prime Time Television in the Gay Nineties." In The Television Studies Reader, by R.C. Allen and A. Hill, 389-403. New York: Routledge.

Colletta, Lisa. 2009. "Political Satire and Postmodern Irony in the Age of Stephen Colbert and Jon Stewart." Journal of Popular Culture, Vol.42, No.5 856-874.

Eloise, Marianne. 2016. "What's So Offensive About 'It's Always Sunny in Philadelphia'? ." PopMatters. March 2. Accessed February 17, 2019. https://www.popmatters.com/itsalways-sunny-in-philadelphia-and-being-offended-by-television-2495452843.html.

Fiske, John. 1988. Television Culture. New York: Routledge.

Gillespie, Marie. 2006. "Narrative Analysis." In Television After TV, by Marie Gillespie, edited by Lynn Spigel and Jan Olsson, 80-87. New York: Open University Press.

Goodman, Tim. 2010. San Francisco Chronicle. September 15. Accessed October 4, 2010. http://www.sfgate.com/cgi-bin/article.cgi?f=/c/a/2010/09/14/DDFM1FD6EF.DTL.

Gournelos, Ted. 2009. "Putppets, Slaves, and Sex Changes: Mr. Garrison and South Park's Performative Sexuality." Television \& New Media, Vol. 10, No.3 270-293.

Griffin, Hollis. 2008. "Queerness, The Quality Audience and Comedy Central's Reno 911!" Television \& New Media, Vol. 9, No.5 355-370.

Hanson, Oliver. 2010. "Mac's 15 Most Unintentionally Gay Moments on Always Sunny." Ranker.com. Accessed March 22, 2019. https://www.ranker.com/list/always-sunny-maclatent-moments/oliverhanson.

Himberg, Julia. 2018. The New Gay for Pay: The Sexual Politics of American Television Production. Austin: University of Texas Press.

Johnson Jr., Michael. 2010. "After Noah's Arc: Where Do We Go From Here." In Queers in American Popular Culture, Vol. 1 Film, TV, Radio, and the Internet, by Jim Elledge. Santa Barbara: Praeger. 
Johnson Jr., Michael. 2016. "The Homoerotics and Monstrous Otherness of Teen Wolf." Studies in Humanities, Vol. 43, No. $1 \& 2$.

Keller, Joel. 2011. "Interview: Rob McElhenney." The AV Club. September 22. Accessed March 20, 2019. https://www.avclub.com/rob-mcelhenney-1798227533.

Kuchera, Ben. 2018. "It's Always Sunny's Season 13 Ends with a Stunning, Erotic Dance Number." Polygon.com. November 8. Accessed March 22, 2019. https://www.polygon.com/2018/11/8/18075598/its-always-sunnys-season-13-mac-dancenumber.

Ladenburg, Kenneth. 2015. "Illuminating Whiteness and Racial Prejudice through Humor in It's Always Sunny in Philadelphia's "The Gang Gets Racist"." Journal of Popular Culture, Vol. 48, No.5 859-877.

Martin Jr., Alfred. 2018. "The Queer Business of Casting Gay Characters on U.S. Television." Communication, Culture and Critique, Vol.11 No.2 282-297.

McComb, Maxwell. 2004. Setting the Agenda: The Mass Media and Public Opinion. Cambridge: Polity Press.

Mellencamp, Patricia. 1997. "Situation Comedy, Feminism and Freud: Discourses of Gracie and Lucy." In Feminist Television Criticism: A Reader, by Charlotte Brunsdon, Julie D'Acci and Lynn Spiegel, 60-73. New York: Oxford University Press.

Mellor, Louisa. 2012. "Why You Need to Watch It's Always Sunny In Philadelphia." Den Of Geek. April 12. Accessed February 17, 2019. https://www.denofgeek.com/tv/21146/whyyou-need-to-watch-its-always-sunny-in-philadelphia.

Metacritic. 2013. It's Alway Sunny In Philadelphia. September 4. Accessed February 17, 2019. https://www.newyorker.com/magazine/2013/11/11/bar-none.

Murray, Noel. 2015. "20 Best 'It's Always Sunny in Philadelphia' Episodes." Rolling Stone. February 20. Accessed February 17, 2019. https://www.rollingstone.com/tv/tv-lists/20best-its-always-sunny-in-philadelphia-episodes-141642/.

Nussbaum, Emily. 2013. "Bar None." The New Yorker, November 11.

Papa, M. J. 2000. "Entertainment-Education and Social Change: An Analysis of Parasocial Interaction, Social Learning, Collective Efficacy and Paradoxical Communication." Journal of Communication 50 (4): 31-55.

Peifer, Jason. 2012. "Can We Be Funny? The Social Resonsibility of Political Humor." Journal of Mass Media Ethics 27 (4): 263-276.

Perkins, Dennis. 2015. "It's Always Sunny In Philadelphia's Wheel of Awfulness Spins Cruelty Into Comic Gold." AV/TV Club. July 29. Accessed February 17, 2019. https://tv.avclub.com/it-s-always-sunny-in-philadelphia-s-wheel-of-awfulness1798282422. 
Schepler, Dianna. 2014. It's Always Sunny In Philadelphis: Scaring Away All the Critics, But Still Adding to 'Our National Conversation'. Brockport: SUNY.

Seles, Sheila. 2009. "It's (Not) The End of TV As We Know It: Understanding Online Television and Its Audience." Convergence Culture Consortium: Comparative Media Studies At Massachusetts Institute of Technology. Accessed June 26, 2012. http://www.convergenceculture.org/weblog/C3\%20Not\%20the\%20End\%20of\%20TV\%2 0White\%20Paper.pdf.

Storm, Jonathan. 2008. "Slacker's Revenge - The Jokers of 'It's Always Sunny In Philadelphia'." The Philadelphia Inquirer. October 16. Accessed February 17, 2019. https://www.philly.com/philly/entertainment/20081016_Jonathan_Storm_Slackers_rev enge.html.

Tanenbaum, Michael. 2018. "Fans, Critics Rave About Dance Masterpiece in 'It's Always Sunny in Philadelphia' Finale ." The Philly Voice. November 8. Accessed March 22, 2019. https://www.phillyvoice.com/its-always-sunny-in-philadelphia-dance-rob-mcelhenneylgbtq-finale-mac-kylie-shea/.

Taylor, Jodie. 2011. "The Intimate Insider: Negotiating the Ethics of Friendship When Doing Insider Research." Qualitative Research, Vol. 11, No.1.

TV Tropes. 2010. Gayngst. May. Accessed March 21, 2019. https:/ttvtropes.org/pmwiki/pmwiki.php/Main/Gayngst.

Venable, Malcolm. 2018. "Mac Is Getting a Boyfriend on It's Always Sunny in Philadelphia." TV Guide. September 5. Accessed February 17, 2019. https://www.tvguide.com/news/macgay-boyfriend-its-always-sunny-in-philadelphia/.

West, Kelley. 2007. Television Blend. September 14. Accessed October 4, 2010. http://www.cinemablend.com/television/TV-Review-It-s-Always-Sunny-In-Philadelphia6345.html.

\footnotetext{
${ }^{1}$ Defined as those viewers who regularly and consistently follow a series from episode to episode and season to season without fail.
} 